\title{
ORGANIZATION REPORT: PRIVATE SCHOOL OF NURSING AT KARACHI, PAKISTAN
}

\author{
Neelam Saleem Punjani \& Sahreen Malik Bhanji \\ The Aga Khan University School of Nursing and Midwifery \\ Corresponding Author Email: neelam.punjani@gmail.com
}

\begin{abstract}
Nursing as a profession today still faces several challenges. There seems a dire need to produce such professional nurses that up bring the dignity of this distinct profession. The heavy responsibility of producing such professional nurses lies in the hands of nursing institutions and primarily the schools and colleges of nursing. The standard of the education offered by these institutions plays an important role in this regard. While addressing at the inaugural ceremony of the Aga Khan University School of nursing and midwifery, His Highness the Aga Khan, chancellor of the Aga Khan University spelt out the vision for the nursing profession in the following words "today, this is the beginning, the birth of a new medical institution in Pakistan, the Aga Khan University... and I hope, this day will also be the dawn of a new dimension for the profession of nursing in Pakistan". Thus it is important that nursing institutions undergo continuous quality assurance process to maintain the high standards of nursing education to develop nurses that can claim their position in this challenging era.
\end{abstract}

\section{KEYWORDS}

Organization Culture, Nursing Schools, Pakistan

\section{INTRODUCTION}

To ensure and evaluate the effectiveness of the nursing schools, we visited two nursing schools in Karachi as part of our educational design course. One was the private college of nursing and the other was the Government College of nursing. As a limitation, only one institution private College of nursing would be addressed in this report. This report presents a brief introduction of the private College of nursing, followed by its vision, mission and philosophy, an account of different aspects of the institution related to infrastructure and resources, programs, curriculum, policies, accreditation and professional development. The last part of the report includes some of the strengths and limitations of the institution along with some proposed recommendations.

\section{BACKGROUND}

Private College of nursing was initially known as school of nursing built as the first academic unit of Private University. It was built in 1986; later in 2009 the school of nursing was upgraded to the level of college of nursing. The school of nursing started with only three programs. Currently it has been successful in implementing eight programs under the umbrella of the college of nursing. These include three degree programs including, an accelerated MScN program, a fast track post RN BScN program, and four years BScN program. Three diploma programs including, three years diploma in general nursing, diploma in nurse midwifery, diploma in pupil midwifery. Two certificate programs including, two years licensed practical nurse and one year paramedical technician program. Brief details of these listed programs would be dealt in a separate section later in this report.

\section{GOVERNANCE AND ADMINISTRATIVE STRUCTURE}

Private College of nursing is affiliated with the Private University. The organogram or administrative structure of Private University starts with the chancellor and the vice chancellor. The chancellor of the university is also the president of the Pakistan Nursing Council (PNC), holds two positions simultaneously. Then comes the dean of different sections like college of nursing, school of dentistry, school of physiotherapy etc. followed by the respective program and course coordinators. The central administration and decision making authority lies within the hands of the chancellor but the Dean college of nursing is responsible for the day to day issues. The Private College of nursing is registered with both the Pakistan Nursing Council (PNC), as well as with the higher education commission (HEC) except for the accelerated maters in nursing program.

\section{VISION, MISSION AND PHILOSOPHY OF THE ORGANIZATION}

The college of nursing envisions being a distinct and autonomous institution aiming to promote excellence, innovation, and critical thinking in graduate nurses to improve patient outcomes. Development of human capacities through discovery and dissemination of knowledge is the mission of this institution. To advance this mission the college of nursing has set several longterm objectives. The philosophical basis of the institution is constant improvement in clinical practice, teaching and research. According to the briefing and the observations, as evidenced by the faculty profiles that all of them are at least $\mathrm{BScN}$ and the initiative of MScN program, it is believed that the college of nursing is well headed towards fulfillment of its vision and mission. As far as the philosophy is concerned, professional development opportunities for the faculty and hiring of $\mathrm{MScN}$ qualified faculty members is a prominent reflection. However, it is still struggling to up bring the status of nursing as a profession as compared to its counter parts.

\section{PROGRAMS, CURRICULUM AND ACCREDITATION}

Currently, Private College of nursing is running a total of eight programs. Firstly, the accelerated masters in nursing ( $\mathrm{MScN}$ ) program which is a fifteen months, thesis based degree program, aiming to prepare academicians who would bring about change in nursing profession through education and quality care (O'Neil, 2009). The program was started on a need basis to get selfsufficient with well-equipped Masters trained faculties to teach in 
various programs. The program is recognized by the PNC but awaiting to be approved by HEC which could be a drawback for the graduates. The candidates must have a BScN or post RN degree from a PNC registered institution with a minimum GPA of 2.5 , seven years of experience, an experience letter and three letters of reference to be eligible in this program The curriculum used for the $\mathrm{MScN}$ program is adopted form PNC with a reduction in the total credit hours and omission of public health nursing and proposal writing courses, electives and practicum. This reduction in the total credit hours is questionable as it might impact the terminal objectives that the program aims to achieve. Moreover, a total of eight MScN students were enrolled up till now but there is only one supervisor for all of them and who is also not a $\mathrm{PhD}$. Second is the four years $\mathrm{BScN}$ degree program which aims to equip students with knowledge, skills and attitudes needed to practice nursing and prepare clinically competent professional nurses. These nurses are expected to utilize critical thinking skills to provide holistic care and uplift the image of nursing profession. It is essential for the candidates to secure at least $50 \%$ marks in Intermediate (pre-medical) to be eligible. The program is offered as a fulltime facility only, for both genders. Third program at the Private College of nursing is the one year fast track $\mathrm{BScN}$ program offered for fulltime male and female students. The eligibility criteria for this program require a diploma in $\mathrm{RN}$ and $\mathrm{RM}$ with a minimum of three years of clinical experience and a specialization for males. The program is designed for the registered nurses and midwives with a diploma with a goal of fulfilling the faculty shortage to teach at the undergraduate level. It is commendable to state here that this year the college of nursing achieved a milestone with all its faculty members holding a $\mathrm{BScN}$ degree. Fourth is the three years diploma in general nursing program which prepares students to deliver safe, competent nursing care to individuals, families and communities. It is a full time program offered for those who have passed their matriculation with a $55 \%$ marks in biology group. Fifth and sixth are the Diploma in nurse midwifery (eighteen months) and diploma in pupil midwifery (one year) programs. The goals of these programs are to train the RN's to reduce the maternal mortality rate and to promote maternal and child health services in the country. Both these programs are offered for female students only. Seventh and eighth are the two certificate programs. The two years licensed practical nurse program prepares the individual to provide safe comprehensive care at primary, secondary and tertiary level within clinical and community setting. The minimum requirement of this program is matric with a $45 \%$ passing marks and is offered for females only. An advantage of this program is to have a handful of practical nurses in times when diploma program is phasing out. The one year paramedical technician program is meant to prepare applicants for providing basic nursing care to patients along with equipment management. This program is recognized by the Sindh medical faculty. It is a full time program offered to students with a $50 \%$ marks in matriculation. It is to be noted that the eligibility criterion and the terminal objectives for the above mentioned programs are according to criteria of the PNC. The curriculum for most of these programs is also from PNC. The college of nursing has a well-established board of studies and a curriculum committee which is responsible for reviewing the curriculum mostly on need basis. However for major changes, proposal is sent to the academic council for final decision. Moreover, faculty and course evaluation is also incorporated timely. Though not much emphasis is laid upon curriculum review as PNC curriculum is used however, incorporation of faculty and student evaluation seems useful in achieving the terminal objectives of the respective programs in a better way.

\section{ORGANIZATIONAL POLICIES, OFFICIAL RECORD SYSTEM AND PUBLICATIONS}

The set of rules and regulations and policies defined by an institute on reflects the discipline and its values. Similarly, the Private College of nursing follows the centralized policies from the Private University. However it has some of its own policies like examination policy and clinical policy etc. The advertisement for admissions into the various programs is placed in the newspaper through which the students enroll themselves for the preadmission test. Successful candidates are then called for an interview after which the final results are announced. No such issues like forceful admissions or admissions based on persona influences was voiced out by the dean which means that the admissions are purely on merit basis which adds to the reputation and credibility of the institution. The approved number of seats by PNC for the degree program: $\mathrm{MScN}$ program is 10 per year whereas for $\mathrm{BScN}$ program is 50 per year. The proportion of male and female seats is also defined by the PNC. At present the total number of students studying in Private College of nursing is 280 . Moreover, the faculty ratio according to PNC is 10:1 but in Private College of nursing due to faculty shortage the approximate faculty versus student ratio is $25: 1$ which could be assumed as the hindering factor for effective learning of students. All the students are expected to abide by the educational, clinical, examination and attendance policies. As per the academic policy, students are expected to have minimum of 2.5 GPA. Those students who fail an examination are allowed for a re-sit exam once and if they still could not make it they are terminated from the program. All the policies are well defined in their prospectus. Moreover, the Private College of nursing has its own administration office which is responsible for keeping and maintaining records of the students, faculties, and alumni. This effort reflects the credibility as well their efforts of preserving the valuable contributions and a record professional achievements of their graduates. However, since it was a one day visit we cannot comment on the compliance and accuracy of these records. Private University has its own official published prospectus which is divided into the different sections that comes under its umbrella. Similarly, there is a section of the college of nursing which comprise of brief details of all its programs, admission criterion and requirements. As far as other official publications are concerned, no such evidence could be found in the limited time period of the visit.

\section{INFRASTRUCTURE AND LEARNING RESOURCES}

The Private College of nursing is a separate campus located near the Private Hospital. The class rooms were spacious and provided with basic facilities like furniture, multimedia, white boards, etc. However, due to the less number of classrooms, skills lab and Computer lab were also utilized as classrooms. It was also observed that computer lab and skill lab were not the appropriate place for teaching learning process due to the unavailability of resources like multimedia and improper seating arrangements; which could hinder the learning process for the students. There was a dean office, faculty office, administrative office, examination office, and a counselor office which were well 
furnished. Moreover, skill lab was equipped with all basic facilities to assist the students' learning of clinical skills. There was also a small computer lab with almost 15 computers and a small library with latest version books and journals along with the digital library for the facilitation of students. One room was assigned for the students of the MScN program which was equipped with a few computers. Besides, there was a big assembly area which was also used for recreational activities. A small tuck shop and a stationary shop too were also there to facilitate the students and the faculty. The infrastructure of building was inclusive of all basic facilities for students however; it was acknowledged by the dean school of nursing that they are in process of finding another building as the current infrastructure does not meet the needs of the large number of students enrolled in different programs.

\section{PERSONAL AND PROFESSIONAL GROWTH OF STUDENTS AND SUPPORT SERVICES}

The students of Private College of nursing are sent to Private Hospital for clinical under the supervision of their clinical faculties in the morning shifts. However, for evening and night shifts the supervision is provided by the staff nurses who are especially trained. Along with this the institution also provides the counseling service to the students and faculties and it is appreciable that they have very senior and trained counselors present in the college. There is also the facility of student's hostel for out station students. Moreover, students are provided medical facilities within the premises of Private hospital. Under the service agreement, the students are required to sign a contract to within which they are bound to serve the institution equal to the years of their studies. This facility exempts them from paying the amount of fees. These students are also provided stipend as an incentive. This facility is also available for the professional growth of their faculty members who can study and work together. Caliskan (2009) highlight the significance of a faculty development model to professionally train and develop nursing faculties to effectively deliver the curriculum to the students and provide them with a supportive learning environment. Through the opportunity to attend seminars, workshops, and symposiums the faculties are encouraged for their own professional development, Private College of nursing does implement this model to some extent but needs to include more opportunities for learning ways to better meet the demands of challenging students, as well as expertise development.

\section{STRENGTHS AND LIMITATIONS}

In such a limited time, it was not practically possible to inspect all the nitty-gritty's of the institution. However, through observations made and the information provided to us it can be assumed that the college is on its ways towards achieving excellence. The first and foremost advantage to the college is the leadership of the dean whose mission was to develop leaders who can be pioneers for the nursing profession. This also proves that the college values the professional development of its students and faculty. Moreover, the dean herself showed the motivation and willingness to enroll herself into the $\mathrm{PhD}$ program that the college of nursing envisions in near future. Furthermore, the enthusiasm and zeal demonstrated by the dean for improvement in various capacities reflects the hard work and a need to achieve competency. The examples of two such programs like the fast track $\mathrm{BScN}$ program and the accelerated Masters programs on need basis, is another achievement for the institution. The programs are evidence that the institution is well aware of its needs and working hard towards achieving its goal. Though it is still struggling hard for the profession to be recognized as its other counterparts as evidenced by the conversation with the dean, yet she was very positive that the institution will achieve this mission in near future. One of the advantages to Private College of nursing is the dual role of its chancellor as the president of PNC. Thus it was not a very difficult task to get its programs recognized with PNC. Though it is an accomplishment that all the programs are recognized and PNC certified, yet, the challenge was convincing HEC in case of the $\mathrm{MScN}$ program. The university is privileged to have the support and assistance from the nursing pioneers who not only provide counseling services for the students but benefit the college with their valuable experience and achievements.

\section{RECOMMENDATIONS}

Along with the strengths, a few gaps were also identified during the visit within the system of private College of Nursing. One of the gaps that we identified was the lack of strategic planning. The $\mathrm{MScN}$ program started without the approval of HEC. According to Kranenburg (2003) in programs like higher studies the process of quality assurance asserts to have an approval from a professional body. Therefore, the quality and the excellence the Private College of nursing wants to achieve are questionable. This can result in the non-recognition of their MScN graduates in market as well as create problems when these graduates will peruse higher education when their degree is not recognized by the education commission in Pakistan. There are also ethical issues attached to this predicament, where student's career and their reliance with the organization are at jeopardy Moreover, the school has the permission to run this program only for three years hence there seems no plan for its sustainability. It is recommended that the Private College of nursing should work on sustainability of the $\mathrm{MScN}$ program as per the requirements of HEC as very few schools of nursing are offering this program and since diploma is phasing out, lot of people are heading towards the degree programs. Moreover, as starting $\mathrm{MScN}$ program in any institution is a huge responsibility and needs commitment; the institution should have Masters Faculty and preferably $\mathrm{PhD}$ faculties. Another issue that needs to be highlighted is the shortage of faculty. According to PNC the student faculty ratio should be 1:20 (Pakistan Nursing Council, 2009) whereas in Private College of nursing this ratio is $1: 25$. It is strongly recommended that they should hire more faculties so that they could fill this gap of teacher student ratio. Furthermore, shortage of faculties can hinder students' learning and they may not get the required attention from their faculties which can be a factor of clinical incompetency. The institution should provide certain incentives to hire and retain their existing faculties. Moreover, $\mathrm{BScN}$ degree in this period of time when diploma is phasing out is not sufficient as at present time the minimum preparation for beginning professional nursing practice is suggested to be baccalaureate degree in nursing (Rattani, 2011). Thus the institution should plan for the higher education of their faculties as well as systematic human resource development strategies as highlighted by Dias (2010) to meet the challenge of shortage of nurse trainers. The next issue faced by Private College of nursing, is the lack of adequate infrastructure to accommodate the increasing number of the students. It is the requirement of PNC to have an adequate number of classrooms and separate skills and 
computer labs for the students (Pakistan Nursing Council 2009), however at Private, both skills and computer labs were used as classrooms, which were congested and inadequate to accommodate the students. It is though an achievement that Private College of nursing is successfully running eight programs. However, it is also equally important for them do extensive strategic planning with long-term future planning before starting new programs in order to avoid such issues of space and enhance student's learning. Lastly, research which one of the most important areas which needs to be addressed by a professional nursing institution heading towards excellence and evidence based practice. As per the guidelines from Pakistan Nursing Council (2009), the nursing institutions need to create sufficient opportunities for nursing students and faculties to participate in research and scholarly activities. Additionally, Phillips (2002) have established that nurses with baccalaureate education demonstrate higher competency in nursing practice, communication, leadership, and research. Thus, it is imperative for Private College of nursing to look into this dimension, encourage and provide opportunities to its faculties and students to engage in research activities in order to achieve distinction.

\section{CONCLUSION}

Though the above mentioned recommendations may be difficult to implement, yet the enthusiasm and positive attitude of the dean and her team of faculties can make it possible. The complexity of processes and the chain of authorities might be an obstacle but since the college of nursing is into the process of improvement and making its voice heard, change would no doubt be difficult but not impossible.

\section{REFERENCES}

- Caliskan, Z. Z., Tabancali, E., (2009). New Curriculums and New Challenges: What do School Administrators Really Do? International Journal of Social Sciences 4 (2) 112- 116.

- Dias, J. M., Ajani, K., \& Mithani, Y. (2010). Conceptualization and operationalization of a baccalaureate nursing curriculum in Pakistan: Challenges; hurdles and lessons learnt. Procedia-Social and Behavioural Sciences, 2(2), 2335-2337.

- O'Neil Mundinger, M., Starck, P., Hathaway, D., Shaver, J., \& Fugate Woods, N. (2009). The ABCs of the doctor of nursing practice: assessing resources, building a culture of clinical scholarship, curricular models. Journal of Professional Nursing, 25(2), 69-74.

- Pakistan Nursing Council. (2009). Minimum criteria, requirement and guidelines including faculty requirement/checklist of infrastructure and equipment. Retrieved on April 29, 2013 from http://www.pnc.org.pk/Rules_for_Degree_Program_Nursing_I nstitutions.htm

- Phillips, C.Y., Palmer, C.V., Zimmerman, B.J. \& Mayfield, M. (2002). Professional development: Assuring growth of RN-toBSN students. Journal of Nursing Education, 41, 282-283.

- Rattani, S. A., Akbarali, L., Velji, S. S., \& Malik, A. (2011). Phasing out the General Nursing Diploma Programme at Aga Khan University School of Nursing Karachi, Pakistan. Procedia-Social and Behavioural Sciences, 15, 30463049 . 